\title{
Feedbacks and mechanisms affecting the global sensitivity of glaciers to climate change
}

\author{
B. Marzeion ${ }^{1}$, A. H. Jarosch ${ }^{2}$, and J. M. Gregory ${ }^{3}$ \\ ${ }^{1}$ Center of Climate and Cryopshere, Institute of Meteorology and Geophysics, University of Innsbruck, Austria \\ ${ }^{2}$ Institute of Earth Sciences, University of Iceland, Reykjavík, Iceland \\ ${ }^{3}$ NCAS-Climate, University of Reading, Reading, and Met Office Hadley Centre, Exeter, UK
}

Correspondence to: B. Marzeion (ben.marzeion@uibk.ac.at)

Received: 31 May 2013 - Published in The Cryosphere Discuss.: 17 June 2013

Revised: 28 November 2013 - Accepted: 1 December 2013 - Published: 7 January 2014

\begin{abstract}
Mass loss by glaciers has been an important contributor to sea level rise in the past, and is projected to contribute a substantial fraction of total sea level rise during the 21st century. Here, we use a model of the world's glaciers to quantify equilibrium sensitivities of global glacier mass to climate change, and to investigate the role of changes in glacier hypsometry for long-term mass changes. We find that 21 st century glacier-mass loss is largely governed by the glacier's response to 20th century climate change. This limits the influence of 21st century climate change on glaciermass loss, and explains why there are relatively small differences in glacier-mass loss under greatly different scenarios of climate change. The projected future changes in both temperature and precipitation experienced by glaciers are amplified relative to the global average. The projected increase in precipitation partly compensates for the mass loss caused by warming, but this compensation is negligible at higher temperature anomalies since an increasing fraction of precipitation at the glacier sites is liquid. Loss of low-lying glacier area, and more importantly, eventual complete disappearance of glaciers, strongly limit the projected sea level contribution from glaciers in coming centuries. The adjustment of glacier hypsometry to changes in the forcing strongly reduces the rates of global glacier-mass loss caused by changes in global mean temperature compared to rates of mass loss when hypsometric changes are neglected. This result is a second reason for the relatively weak dependence of glacier-mass loss on future climate scenario, and helps explain why glaciermass loss in the first half of the 20th century was of the same order of magnitude as in the second half of the 20th century, even though the rate of warming was considerably smaller.
\end{abstract}

\section{Introduction}

Glaciers ${ }^{1}$ have lost a substantial fraction of their mass during the past century (Cogley, 2009; Marzeion et al., 2012), with the globally averaged mass balance turning negative probably around 1850 (Leclercq et al., 2011). Within the 20th century, mass loss of glaciers was likely the largest single cause of sea level rise, followed by thermal expansion of the ocean, mass loss of the Greenland and Antarctic ice sheets, and changes in terrestrial water storage (Gregory et al., 2013). Even though the rise of global mean air temperature accelerated in the 20th century, the mass loss rate of glaciers during the second half of the 20th century was not higher than during the first half of the century (Leclercq et al., 2011; Marzeion et al., 2012).

Mass loss from glaciers will continue to contribute to sea level rise substantially during the 21 st century, even though their total sea level rise potential is limited by their total mass. The total ice mass in glaciers is estimated as $35 \pm 7 \mathrm{~cm}$ sea level equivalent (SLE, Grinsted, 2013), $43 \pm 6 \mathrm{~cm}$ SLE (Huss and Farinotti, 2012), 41-52 cm SLE (depending on the assumed fraction of ice caps, Radić et al., 2013), or $49 \pm 6 \mathrm{~cm}$ SLE (by Marzeion et al., 2012, including the mass estimate for peripheral glaciers in Antarctica from Radić et al., 2013). Driven by climate scenarios obtained from the

\footnotetext{
${ }^{1}$ In using the term glaciers, we are referring to global glaciers and ice caps with the exclusion of the Antarctic and Greenland ice sheets, but including Greenland peripheral glaciers and ice caps. Antarctic peripheral glaciers are not included because of the lack of long-term climate observations, which we rely on for model calibration and validation.
} 
Coupled Model Intercomparison Project phase 5 (CMIP5) database, and depending on the emission scenario applied (see van Vuuren et al., 2011, for an overview of the different Representative Concentration Pathways, RCPs), the contribution of glaciers to sea level rise during the 21 st century is estimated as $16 \pm 4 \mathrm{~cm}$ SLE (RCP4.5) to $22 \pm 4$ (RCP8.5) by Radić et al. (2013), or as $15 \pm 4 \mathrm{~cm}$ SLE (RCP2.6) to $22 \pm 5 \mathrm{~cm}$ SLE (RCP8.5) by Marzeion et al. (2012). Remarkably, there is considerable overlap of the uncertainty ranges of projected mass loss from glaciers even for very different climate scenarios. For instance, RCP2.6 and RCP8.5, which during the period 2081-2100 arrive at a global mean temperature change of $1.2 \pm 0.4 \mathrm{~K}$ and $3.8 \pm 0.8 \mathrm{~K}$ respectively relative to 1986-2005. The overlap of uncertainty ranges in glacier projections for these scenarios is not caused by the uncertainties of the glacier models. It is rather the large spread of the ensemble of climate projections used to drive the glacier models, which gives a spread in glacier-mass loss projections that is relatively large compared to the ensemble mean. Moreover, the rates of mass loss projected for the different RCP scenarios are relatively similar during the 21 st century. The latter also reflects the result that over long timescales, there was no simple relation between rates of glacier-mass loss and temperature change during the 20th century (Leclercq et al., 2011; Marzeion et al., 2012).

There are a number of assessments that explain some of the mechanisms responsible for this behavior. For example, Huss (2012) points out that in the Alps during the period 1900-2011, the mass balance year of 2003 had the most negative specific mass balances, but the greatest loss of ice volume occurred in 1947, when the glacier surface area was considerably larger. However, it is not only changes in surface area that change a glacier's response to climate forcing over time: dynamic changes in ice thickness and terminus elevation, reflected together in changes of the ice surface topography, feed back to the mass balance and dampen (in case of terminus elevation) or enhance (in case of thickening/thinning) the glacier's response to climate forcing (Huss et al., 2012). Paul (2010) comes to a similar conclusion that without changes in glacier hypsometry, mass balances in the Alps since 1850 would have been two to three times more negative than observed. This issue has also been discussed in detail by Leclercq et al. (2010) and Huss et al. (2010).

Since dynamic adjustments of a glacier's hypsometry to changed forcing do not happen instantaneously, glaciers may be found out of balance with climate forcing long after a change in the climate forcing occurred. Jóhannesson et al. (1989) and Oerlemans (2001) developed different frameworks that allow the estimation of the response time of a glacier's hypsometry to changes in climate forcing. Zuo and Oerlemans (1997) pointed out that an imbalance between the states of glaciers and climate may be an important factor for sea level rise, and Oerlemans et al. (1998) investigated the dependence of mass balance response of 12 glaciers to hypsometric changes using an ice flow model.
But to date, there are no studies that quantify how mass balances of glaciers are influenced by these mechanisms on a global scale, that is, to what extent present and future sea level rise from glaciers reflects past climate change, and to what extent past and future sea level rise from glaciers is influenced by the feedback of glacier hypsometric changes on glacier mass balance. In order to illuminate these issues, we use the global glacier model of Marzeion et al. (2012) which captures most of the relevant mechanisms required to study the glaciers' response to a number of idealized climate forcings. We briefly describe the glacier model in Sect. 2. In Sect. 3, we present experiments determining equilibrium sensitivities of the world's glaciers, including a distinction of the effects of changes in temperature and precipitation. The effect of glacier hypsometry changes on the response of glaciers to future climate change is investigated in Sect. 4. We discuss the results in Sect. 5 and conclude in Sect. 6.

\section{Description of the glacier model}

The glacier model is based on calculating the annual specific mass balance $B$ for each of the world's individual glaciers as

$B=\left[\sum_{i=1}^{12}\left[P_{i}^{\text {solid }}-\mu^{*} \cdot \max \left(T_{i}^{\text {terminus }}-T_{\text {melt }}, 0\right)\right]\right]-\beta^{*}$,

where $P_{i}^{\text {solid }}$ is the monthly solid precipitation onto the glacier surface per unit area, which depends on the monthly mean total precipitation and the temperature range between the glacier's terminus and highest elevations (i.e., temperature at terminus elevation below a certain threshold implies all precipitation is solid, temperature at the glacier's maximum elevation above the threshold implies all precipitation is liquid, and within that temperature range, the precipitation fraction is interpolated linearly; see Marzeion et al. (2012) for a detailed description), $\mu^{*}$ is the glacier's temperature sensitivity, $T_{i}^{\text {terminus }}$ is the monthly mean air temperature at the glacier's terminus, $T_{\text {melt }}$ is the monthly mean air temperature above which ice melt is assumed to occur, and $\beta^{*}$ is a bias correction (see below). The model does not attempt to capture the full energy balance at the ice surface, but relies on air temperature as a proxy for the energy available for melt (Ohmura, 2001; Hock, 2003; Sicart et al., 2008). $P_{i}^{\text {solid }}$ and $T_{i}^{\text {terminus }}$ are determined based on gridded climate observations (New et al., 2002; Mitchell and Jones, 2005), to which temperature and precipitation anomaly fields from CMIP5 models are added, depending on the experiment performed (see descriptions of experimental setup in Sects. 3 and 4). Changes affecting the glacier hypsometry (i.e. changes in its volume, surface area, and elevation range) are reflected in the determination of $P_{i}^{\text {solid }}$ and $T_{i}^{\text {terminus }}$, are modeled based on $B$, and on linearly adjusting the glacier's surface area and length towards their respective values obtained from volumearea and volume-length scaling (Bahr et al., 1997; Bahr, 
1997); that is, the surface area change $\mathrm{d} A$ of a glacier during each mass balance year $t$ is calculated as

$\mathrm{d} A(t)=\frac{1}{\tau_{\mathrm{A}}(t)}\left(\left(\frac{V(t+1)}{c_{\mathrm{A}}}\right)^{1 / \gamma}-A(t)\right)$,

where $\tau_{\mathrm{A}}(t)$ is the area relaxation timescale (see Eq. 5), $V(t+1)$ is the glacier's volume at the end of the mass balance year, $c_{\mathrm{A}}=0.0340 \mathrm{~km}^{3-2 \gamma}$ (for glaciers), $c_{\mathrm{A}}=$ $0.0538 \mathrm{~km}^{3-2 \gamma}$ (for ice caps), $\gamma=1.375$ (for glaciers), $\gamma=$ 1.25 (for ice caps) are scaling parameters (Bahr et al., 1997; Bahr, 1997), and $A(t)$ is the surface area of the glacier at the end of the preceding mass balance year. Similarly, length changes $\mathrm{d} L$ (and terminus elevation changes associated with them) during each mass balance year are estimated as

$\mathrm{d} L(t)=\frac{1}{\tau_{\mathrm{L}}(t)}\left(\left(\frac{V(t+1)}{c_{\mathrm{L}}}\right)^{1 / q}-L(t)\right)$,

where $\tau_{\mathrm{L}}(t)$ is the length relaxation timescale (see Eq. 4), $c_{\mathrm{L}}=0.0180 \mathrm{~km}^{3-q}$ (for glaciers), $c_{\mathrm{L}}=0.2252 \mathrm{~km}^{3-q}$ (for ice caps), $q=2.2$ (for glaciers), $q=2.5$ (for ice caps) are scaling parameters (Bahr et al., 1997; Bahr, 1997), and $L(t)$ is the glacier's length at the start of the mass balance year. The glacier length response timescale $\tau_{\mathrm{L}}$ is estimated following Jóhannesson et al. (1989) as

$$
\tau_{\mathrm{L}}(t)=\frac{V(t)}{\sum_{i=1}^{12} \int P_{i, \mathrm{clim}}^{\mathrm{solid}}},
$$

where $\int P_{i, \text { clim }}^{\text {solid }}$ is the monthly climatological solid precipitation integrated over the glacier surface area, calculated over the preceding $30 \mathrm{yr}$. The glacier area response timescale is estimated as

$\tau_{\mathrm{A}}(t)=\tau_{\mathrm{L}}(t) \frac{A(t)}{L(t)^{2}}$

based on the assumption that area changes caused by glacier width changes occur instantaneously, while area changes caused by glacier length changes occur with the timescale of glacier length response.

The volume change $\mathrm{d} V$ of a glacier in year $t$ is calculated as

$\mathrm{d} V(t)=B(t) \cdot A(t)$.

The temperature sensitivity $\mu^{*}$ is determined from observed past variations for each of the glaciers with available mass balance in Cogley (2009). In that data set, there is a global total of 255 glaciers that have all the metadata needed for the parameter estimation, are covered by the temperature and precipitation data set we use (see below), are indicated to be reliable by the status flag of the data set, and have at least two annual mass balance measurements. The procedure is as follows. We assume that there exists some $31 \mathrm{yr}$ reference period, centered on year $t^{*}$, whose climatology is such that the glacier with its present-day hypsometry would be in equilibrium (i.e., with its mass not changing). For this reference period, by construction

$$
\begin{aligned}
B & =\sum_{i=1}^{12}\left[P\left(t^{*}\right)_{i, \text { clim }}^{\text {solid }}-\mu\left(t^{*}\right)\right. \\
& \left.\cdot\left(\max \left(T\left(t^{*}\right)_{i, \text { clim }}^{\text {terminus }}-T_{\text {melt }}, 0\right)\right)\right]=0,
\end{aligned}
$$

where $P\left(t^{*}\right)_{i, \text { clim }}^{\text {solid }}$ and $T\left(t^{*}\right)_{i, \text { clim }}^{\text {terminus }}$ are the monthly climatological values of $P_{i}^{\text {solid }}$ and $T_{i}^{\text {terminus }}$, during the $31 \mathrm{yr}$ period centered around the year $t^{*}$. Note that we do not assume $t^{*}$ to be a time at which the glacier was actually in balance. If the climate has been warming and the glacier retreating, as is generally the case, $t^{*}$ would be in the past, and the glacier actually would have had a negative mass balance at time $t^{*}$. The assumption is that if the climate of time $t^{*}$ had been maintained, the glacier eventually would have contracted until it reached its present-day hypsometry.

We obtain a total of 109 monthly climatologies of precipitation and temperature (the data set of Mitchell and Jones (2005) provides $109 \mathrm{yr}$ of monthly precipitation and temperature; at the end and beginning of the time series, the climatologies are calculated over shorter time periods), and subsequently obtain an estimate of $\mu$ from Eq. (7) for each of the 109 choices of $t^{*}$. We then apply the glacier model to all glaciers for which direct mass balance observations are available, for each of the 109 possible values of $\mu(t)$. For each of these glaciers, we identify $t^{*}$ as that time, for which applying the corresponding temperature sensitivity $\mu^{*} \equiv \mu\left(t^{*}\right)$ yields the smallest mean error of the modeled mass balances. This minimum difference is denoted by $\beta^{*}$.

For glaciers without observed mass balances (i.e., the vast majority of glaciers), $t^{*}$ is interpolated from surrounding glaciers with mass balance observations, and $\mu^{*}$ is subsequently determined from solving Eq. (7) for $\mu^{*}$, using precipitation and temperature obtained from the climatology centered around the interpolated value of $t^{*}$.

The bias correction $\beta^{*}$ is determined by interpolating the minimized bias obtained during the determination of $t^{*}$ from surrounding glaciers with mass balance observations. A cross validation of the determination of $\mu^{*}$ shows that the spatial interpolation of $t^{*}$ leads to substantially smaller errors than the spatial interpolation of $\mu^{*}$ (Marzeion et al., 2012). This can be understood as an effect of neighboring glaciers experiencing a similar history of climate forcing, but having potentially very different temperature sensitivities.

Given any pair of glaciers for which the historical calibration is carried out, we may calculate the temporal correlation between the annual time series for those two glaciers of the errors in the modeled mass balance. Considering all such pairs, we can calculate the correlation of this temporal error correlation with the distance between the two glaciers. This 
latter correlation is 0.008 , indicating that the model errors for the individual glaciers can be treated as independent of each other. Taking the temporal correlation between the annual time series of the mass balances instead of the errors of the modeled mass balances, and calculating the correlation of this temporal mass balance correlation with the distance between the two glaciers, we obtain a value of -0.209 . This indicates that correlations of the mass balances of neighboring glaciers do not transfer to correlations in the errors of the modeled mass balances.

Initial values for surface area and elevation distribution of a glacier are obtained by draping ice outlines from the Randolph Glacier Inventory (RGI, Arendt et al., 2012) version 1 over version 2 of the ASTER global digital elevation model (GDEM), applying a suitable watershed algorithm (Ehlschlaeger, 1989) to separate ice complexes into individual glaciers, and extracting glacier elevation statistics (minimum, mean and maximum elevation) from the GDEM. The model accounts for the differing dates of surface area measurement in the RGI by ensuring that the observed glacier extent is reproduced in the year of observation. The initial volume at the start of the model run is determined from this constraint: iteratively, we determine the ice volume (as well as surface area, length and terminus elevation, following the scaling relations mentioned above) at the start of the simulation that yields the observed surface area in the year of observation. Unless mentioned otherwise, all the runs of the glacier model presented here were initialized using the "historical" experiment of the respective CMIP5 model.

A more detailed and complete description of the determination of the model's parameters, both glacier specific and global, and a comprehensive validation of the model can be found in Marzeion et al. (2012). Uncertainties of the modeled results are obtained by propagating the uncertainties of the modeled specific mass balance, which are determined independently during a leave-one-glacier-out cross validation, through the entire model system, also taking into account uncertainties of the representation of the dynamic glacier response to volume changes. The propagated and temporally accumulated uncertainties themselves are also independently validated using geodetically measured volume and surface area changes (see Marzeion et al., 2012).

\section{Equilibrium sensitivities}

\subsection{Experimental setup and forcing}

Results from 15 different CMIP5 experiments (see Table 1) were used to force the glacier model in the equilibrium experiments with constant climate over a range of global mean temperature anomalies. For each of the RCP8.5 experiments, monthly anomaly fields of precipitation and near-surface air temperature were determined relative to the monthly climatology of 1961 to 1990 . Then, monthly climatologies of the anomalies were determined for each overlapping $30 \mathrm{yr}$ period contained in the combined historical and RCP8.5 experiment (i.e., between 1850 or 1860 and 2100 or 2300, depending on the climate model, see Table 1). From this data set, the climatological anomaly fields of precipitation and temperature were extracted for global mean temperature anomalies of 1 to $10 \mathrm{~K}$. (The number of fields extracted from each CMIP5 experiment therefore depends on the maximum global temperature anomaly reached over a 30 year mean, and since the global mean temperature anomalies do not necessarily contain the required integer anomalies, we took the anomaly field with the smallest difference in global mean temperature anomaly. This difference is smaller than $0.1 \mathrm{~K}$ for all cases.) These anomaly fields were added to the observed climatological fields of New et al. (2002) to obtain the climate forcing for the glacier model. Additionally, the glacier model was forced by the observed climatological fields of New et al. (2002) only (i.e., without any modeled anomalies, giving a global mean anomaly of $0 \mathrm{~K}$ ).

To obtain the equilibrium response of the glaciers to constant climate forcing, the same forcing was repeatedly applied for each glacier until volume changes of the glacier became negligible. This was defined to be the case when the volume change over the last 100 modeled years was smaller than $1 \%$ of the glacier volume. Reaching the equilibrium took up to approximately $700 \mathrm{yr}$ for some glaciers. On the global scale, ice volume changes are small after $200 \mathrm{yr}$ (Fig. 1). Note that in an experimental setup like this, glaciers may reach an equilibrium, while the state of the climate system that was used to drive the glaciers into equilibrium is not itself an equilibrium.

The equilibrium state of the glaciers will be a response both to temperature and precipitation changes. Additionally, the effect of precipitation changes will potentially be modified by temperature through changes in the fraction of solid to liquid precipitation. In order to isolate the effects of both, the experiment was repeated once applying only the temperature anomaly fields (i.e., ignoring any precipitation anomalies resulting from future climate change), and once applying only the precipitation anomaly fields (i.e., ignoring the temperature anomalies).

\subsection{Results}

Figure 2 shows the resulting equilibrium volume changes of the worlds glaciers as a function of global mean temperature anomaly ${ }^{2}$. When forced with the observed climatology of 1961 to 1990 , glaciers would lose mass corresponding to

\footnotetext{
${ }^{2}$ Peripheral glaciers in Antarctica cannot be modeled by our model because the climate data sets of New et al. (2002) and Mitchell and Jones (2005) do not cover Antarctica. Marzeion et al. (2012) estimated volume change of peripheral glaciers of Antarctica by upscaling. Since snow fall increase may dominate increased melt (Barrand et al., 2013), this may be problematic, and we excluded Antarctic peripheral glaciers here. For a direct comparison
} 
Table 1. CMIP5 models and experiments used for forcing.

\begin{tabular}{llllll}
\hline Models & Historical & RCP2.6 & RCP4.5 & RCP6.0 & RCP8.5 \\
\hline bcc-csm1-1 & $1850-2005$ & $2006-2300$ & $2006-2300$ & $2006-2100$ & $2006-2300$ \\
CanESM2 & $1850-2005$ & $2006-2300$ & $2006-2300$ & - & $2006-2100$ \\
CCSM4 & $1850-2005$ & $2006-2100$ & $2006-2100$ & $2006-2100$ & $2006-2100$ \\
CNRM-CM5 & $1850-2005$ & $2006-2100$ & $2006-2300$ & - & $2006-2300$ \\
CSIRO-Mk3-6-0 & $1850-2005$ & $2006-2100$ & $2006-2300$ & $2006-2100$ & $2006-2300$ \\
GFDL-CM3 & $1860-2005$ & $2006-2100$ & $2006-2100$ & $2006-2100$ & $2006-2100$ \\
GISS-E2-R & $1850-2005$ & - & $2006-2300$ & $2006-2100$ & $2006-2300$ \\
HadGEM2-ES & $1860-2005$ & $2006-2300$ & $2006-2300$ & $2006-2099$ & $2006-2300$ \\
inmcm4 & $1850-2005$ & - & $2006-2100$ & - & $2006-2100$ \\
IPSL-CM5A-LR & $1850-2005$ & $2006-2300$ & $2006-2300$ & $2006-2100$ & $2006-2300$ \\
MIROC5 & $1850-2005$ & $2006-2100$ & $1850-2100$ & $2006-2100$ & $2006-2100$ \\
MIROC-ESM & $1850-2005$ & $2006-2100$ & $2006-2100$ & $2006-2100$ & $2006-2100$ \\
MPI-ESM-LR & $1850-2005$ & $2006-2300$ & $2006-2300$ & - & $2006-2300$ \\
MRI-CGCM3 & $1850-2005$ & $2006-2100$ & $2006-2100$ & $2006-2100$ & $2006-2100$ \\
NorESM1-M & $1850-2005$ & $2006-2100$ & $2006-2300$ & $2006-2100$ & $2006-2100$ \\
\hline
\end{tabular}

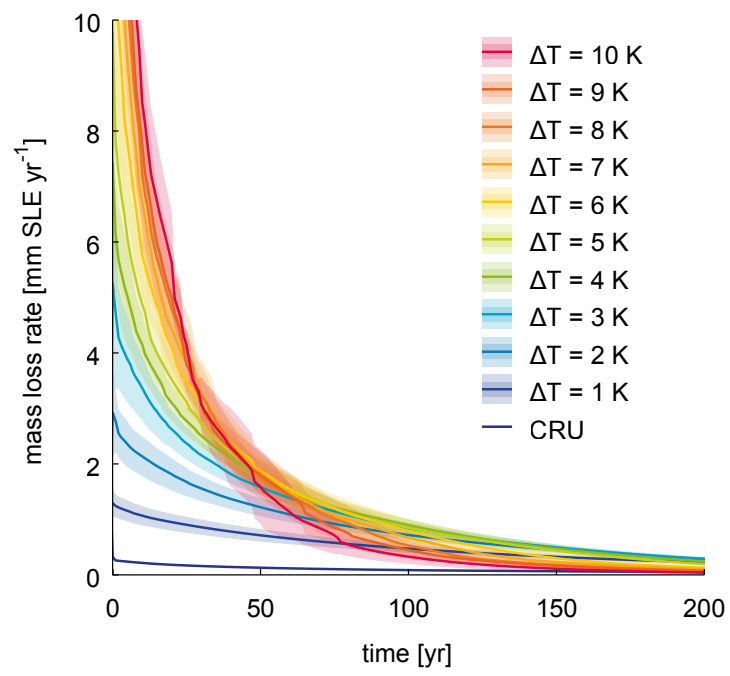

Fig. 1. Rates of global glacier-mass loss during the first $200 \mathrm{yr}$ of the equilibrium experiment (Fig. 2). Solid lines show model mean, shading indicates one standard deviation. Colors indicate global mean temperature anomaly applied. CRU corresponds to the experiment where the observed climatology is applied (i.e., $\Delta T=0 \mathrm{~K}$ ). The volume response within the first $200 \mathrm{yr}$ is generally $>95 \%$ of the total.

$6.6 \pm 0.2 \mathrm{~cm}$ SLE before reaching a new equilibrium. Note that the uncertainty range given - one standard error - to a large degree depends on the timescale of glacier adjustment in this experimental setup, since errors are accumulated over time. The equilibrium sensitivity to small temperature and associated precipitation changes with respect to the climatology is $10.5 \pm 2.3 \mathrm{~cm} \mathrm{SLE} \mathrm{K}^{-1}$ (see Table 2) with consider-

with the results of Marzeion et al. (2012), apply a scaling factor of $1.22 \pm 0.01$ to the volume change estimates presented here.

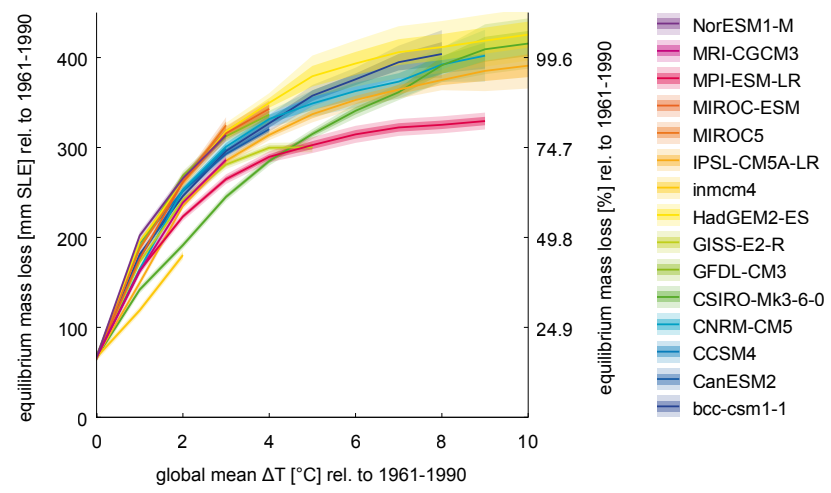

Fig. 2. Equilibrium mass loss of glaciers as a function of global mean temperature anomaly. Dark (light) shading indicates one (two) standard errors. Colors indicate which CMIP5 model was used for forcing. The volume estimates differ slightly between the models. Therefore, the mean of the volume estimates was used for the right axis, and values $>100 \%$ may occur for individual models.

able differences between different climate models. The sensitivity decreases to zero for progressively larger temperature changes, because of the reduction in the ice mass that remains to be removed.

Generally speaking, global mean precipitation increases with increasing global mean temperatures (e.g., Andrews et al., 2010). It can therefore be expected that the precipitation anomalies associated with the warming dampen the glacier equilibrium response to the warming. This is confirmed in Fig. 3, showing the additional equilibrium mass loss when precipitation anomalies from the climate model are not applied to the glacier model. Increasing precipitation decreases the glacier sensitivity by $1.2 \pm 0.3 \mathrm{~cm} \mathrm{SLE} \mathrm{K}^{-1}$ (see Table 2), again with considerable differences between the climate models. But for warming greater than $1 \mathrm{~K}$ this 
Table 2. Equilibrium sensitivities obtained as the difference between the equilibrium states at global mean $\Delta T=0 \mathrm{~K}$ and global mean $\Delta T=1 \mathrm{~K}$, and the anomalies of these sensitivities when either precipitation or temperature anomalies are ignored.

\begin{tabular}{|c|c|c|c|}
\hline Model & $\begin{array}{r}\text { Equilibrium sensitivity } \\
{\left[\mathrm{mm} \mathrm{SLE} \mathrm{K}^{-1}\right]}\end{array}$ & $\begin{array}{r}\Delta \text { (equi. sensitivity) } \\
{\left[\mathrm{mm} \mathrm{SLE} \mathrm{K}^{-1}\right] \text { at } P=\text { const. }}\end{array}$ & $\begin{array}{r}\Delta \text { (equi. sensitivity) } \\
{\left[\mathrm{mm} \mathrm{SLE} \mathrm{K}^{-1}\right] \text { at } T=\text { const. }}\end{array}$ \\
\hline bcc-csm1-1 & $114.4 \pm 3.1$ & $15.7 \pm 5.4$ & $-132.7 \pm 5.5$ \\
\hline CanESM2 & $111.1 \pm 3.1$ & $12.6 \pm 5.4$ & $-127.3 \pm 5.5$ \\
\hline CCSM4 & $127.4 \pm 3.1$ & $10.2 \pm 5.4$ & $-137.3 \pm 5.4$ \\
\hline CNRM-CM5 & $97.9 \pm 3.1$ & $14.8 \pm 5.5$ & $-125.9 \pm 5.4$ \\
\hline CSIRO-Mk3-6-0 & $75.2 \pm 3.1$ & $11.9 \pm 5.4$ & $-86.1 \pm 5.4$ \\
\hline GFDL-CM3 & $122.8 \pm 3.1$ & $13.4 \pm 5.4$ & $-136.0 \pm 5.4$ \\
\hline GISS-E2-R & $105.9 \pm 3.1$ & $13.1 \pm 5.4$ & $-121.1 \pm 5.4$ \\
\hline HadGEM2-ES & $128.5 \pm 3.1$ & $10.7 \pm 5.5$ & $-144.2 \pm 5.5$ \\
\hline inmem4 & $52.2 \pm 3.1$ & $14.4 \pm 5.4$ & $-75.8 \pm 5.4$ \\
\hline IPSL-CM5A-LR & $82.8 \pm 3.1$ & $14.6 \pm 5.4$ & $-99.6 \pm 5.5$ \\
\hline MIROC5 & $120.9 \pm 3.1$ & $6.3 \pm 5.4$ & $-135.5 \pm 5.4$ \\
\hline MIROC-ESM & $109.5 \pm 3.2$ & $13.3 \pm 5.5$ & $-124.3 \pm 5.4$ \\
\hline MPI-ESM-LR & $96.5 \pm 3.1$ & $10.2 \pm 5.4$ & $-113.6 \pm 5.4$ \\
\hline MRI-CGCM3 & $95.5 \pm 3.1$ & $9.4 \pm 5.5$ & $-119.6 \pm 5.6$ \\
\hline NorESM1-M & $135.3 \pm 3.1$ & $7.2 \pm 5.4$ & $-151.1 \pm 5.4$ \\
\hline Mean \pm std. dev. & $105.1 \pm 22.5$ & $11.8 \pm 2.8$ & $-122.0 \pm 20.9$ \\
\hline
\end{tabular}

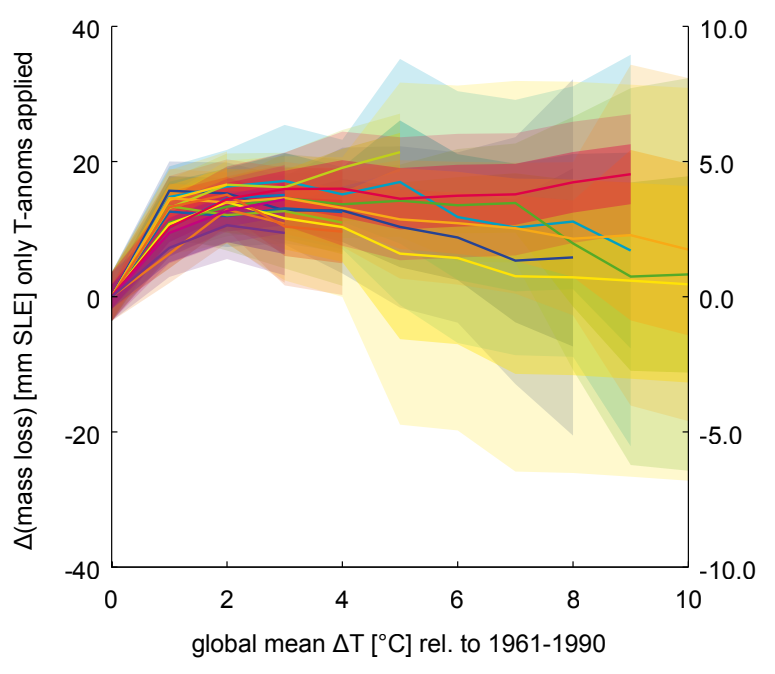

Fig. 3. Additional equilibrium mass loss of glaciers when only temperature anomalies are applied, and precipitation anomalies are ignored. Dark (light) shading indicates one (two) standard errors. Colors as in Fig. 2.

dampening effect of precipitation becomes smaller, even though precipitation can be expected to increase further. The reason is that with higher temperatures an increasing fraction of precipitation is liquid and does not contribute to glacier mass gain. At very high temperature anomalies, essentially all precipitation falling at the glaciers becomes liquid, such that changes in the amount of precipitation do not affect glacier mass balance in our model, since energy input from liquid precipitation was neglected.

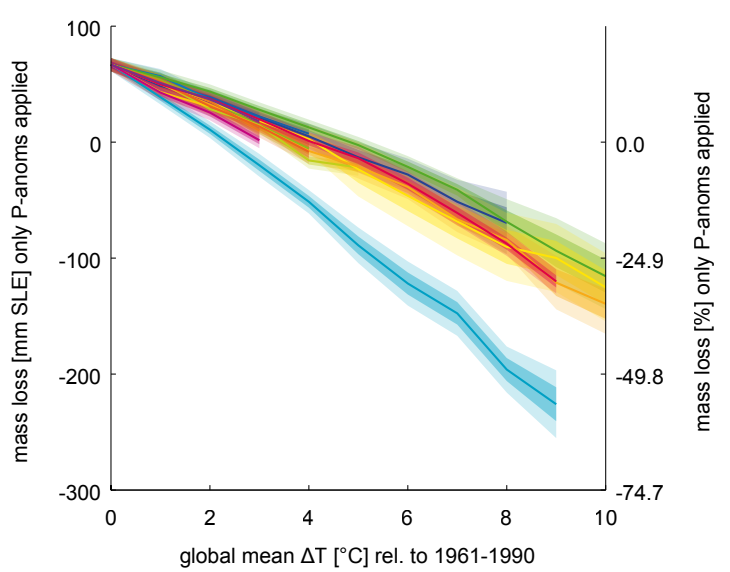

Fig. 4. Equilibrium mass loss (negative numbers imply mass gain) of glaciers when temperature anomalies are ignored, and only precipitation anomalies associated with the temperature anomalies are applied. Dark (light) shading indicates one (two) standard errors. Colors as in Fig. 2.

It would therefore be wrong to assume that precipitation anomalies at the glacier sites are small - it is just that much of the increasing precipitation is liquid because of the increased temperatures: Fig. 4 shows the equilibrium mass loss of glaciers when temperature anomalies are ignored (i.e., negative values imply glacier mass gain). If the warming is ignored, precipitation changes associated with $4 \mathrm{~K}$ global mean temperature change would roughly compensate for the mass loss that would occur in response to the temperatures of the 1961-1990 reference period, and glaciers would stabilize at their present-day extent. 

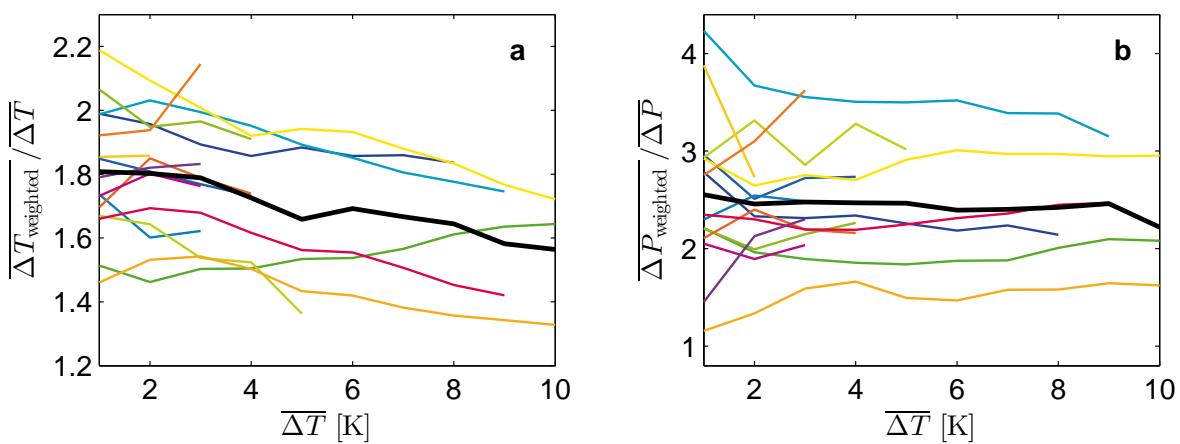

Fig. 5. Temperature and precipitation amplification at the locations of glaciers. (a) Annual mean amplification of temperature anomalies at the locations of glaciers as a function of global mean temperature anomaly $\overline{\Delta T}$. (b) Annual mean amplification of relative precipitation anomalies at the locations of glaciers as a function of global mean temperature anomaly $\overline{\Delta T}$. Colors as in Fig. 2.

To understand this rather strong effect of precipitation changes, it is helpful to set the global mean changes of temperature and precipitation into relation with the changes experienced by glaciers. Figure 5a shows the ratio of glacier surface area weighted mean temperature anomaly to global mean temperature anomaly for each climate model as a function of global mean temperature change. While there are strong differences between climate models, all of them project greater than average warming at the glacier sites, particularly at low temperature changes. The mean amplification factor at small temperature changes is 1.8 (i.e., at a global mean temperature change of $2 \mathrm{~K}$, glaciers experience a mean temperature change of $3.6 \mathrm{~K}$ ). This temperature amplification is easily explained by the geographical distribution of glaciers, which all are situated on land, which on average experiences a greater warming than the global mean (e.g., Sutton et al., 2007), and a large fraction of glaciers is located at high northern latitudes, where warming is also greater than at lower latitudes (e.g., Manabe et al., 1991). Since this Arctic temperature amplification to a large degree is caused by albedo reduction through loss of sea ice (Screen and Simmonds, 2010) and seasonal snow cover, it is consistent that the amplification factor experienced by glaciers decreases for high global mean temperature changes, since sea ice and snow cover lost at lower temperatures may no longer influence the local albedo.

Glaciers are projected to experience an even stronger amplification of precipitation (Fig. 5b). The spread between the different climate models is even larger than for temperature, and the amplification is nearly independent of temperature. The positive correlation between temperature and precipitation anomalies is determined by the energy balance of the troposphere (Andrews et al., 2010).

\section{Feedbacks of glacier hypsometry and mass balance}

\subsection{Experimental setup and forcing}

All the projections of global glacier mass change during the 21st to 23rd centuries presented in Marzeion et al. (2012) were repeated,

- once ignoring all the effects of glacier-mass loss or gain on glacier hypsometry (i.e., glacier surface area and elevation distribution were held constant in time), as obtained from the RGI and GDEM, and glacier volume was treated as infinite, allowing the glacier to respond to changed climate forcing independent of the history of climate forcing;

- and once including all the effects of glacier-mass loss or gain on glacier hypsometry except for the terminus elevation, which was held constant in time, as obtained from the RGI and GDEM (i.e., surface area and volume evolving with time).

The results of these experiments were then compared to the results of Marzeion et al. (2012) who account for terminus elevation changes, surface area changes, and volume changes, in order to isolate and quantify the feedbacks of glacier hypsometry change with mass balance.

\subsection{Results}

\subsubsection{Constant hypsometry, infinite ice volume}

If all aspects of a glacier's hypsometry are held constant in time, and ice volume is treated as infinite, the glacier is prevented from approaching an equilibrium with climate forcing, and subjecting the glacier to climate change essentially becomes equivalent to transplanting a glacier into a future climate, without taking into account the temporal evolution of climate and glacier change that lead there. In this scenario, rates of glacier-mass loss are easier to understand than 

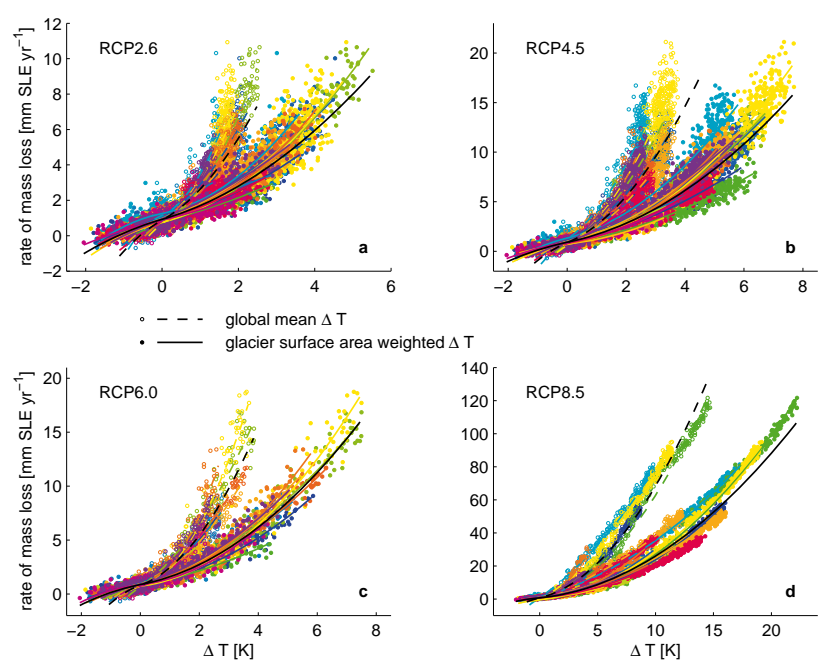

Fig. 6. Global glacier mass balance, expressed in terms of global mean sea level equivalent (SLE), as a function of anomalies in (1) global mean (open circles, dashed lines) and (2) glacier area weighted (filled dots, solid lines) temperature. Results refer to the constant hypsometry, infinite volume scenario. Colored lines show quadratic fits for each individual CMIP5 model, black lines show fits based on mean parameters of colored lines. Colors as in Fig. 2. Different panels refer to different RCPs.

accumulated mass loss, and shown in Fig. 6. Independent of the applied scenario and climate model, rates of mass loss increase (for positive temperature anomalies) or decrease (for negative temperature anomalies) roughly quadratical with temperature. A quadratic relation can be expected from Eq. (1), where both solid fraction of precipitation and monthly ablation, and length of the accumulation and ablation seasons, are related almost linearly to temperature (within certain bounds). We therefore fitted a quadratic function for all scenarios and all models, once using the global mean, and once using glacier surface area weighted temperature anomaly.

Table 3 summarizes the parameters of the function, showing the mean parameter values of the different CMIP5 models, and the standard deviation. We find a contribution of roughly $0.85 \mathrm{~mm} \mathrm{SLE} \mathrm{yr}^{-1}$ mass loss independent of $\Delta T$ that corresponds to the adjustment of glaciers to past climate change, as discussed in Sect. 3, and is therefore independent of temperature anomalies. This contribution implies substantial future glacier-mass loss even without further warming. The magnitude here however is substantially higher than the magnitude of the mass loss rates found in the equilibrium experiments (the line corresponding to "CRU" in Fig. 1, on the order of $0.5 \mathrm{~mm} \mathrm{SLE} \mathrm{yr}^{-1}$ at the start of the experiment), indicating that glacier hypsometry changes dampen the glaciers response to climate change.

A further contribution is linearly related to temperature anomalies, and on the order of $0.61 \mathrm{~mm} \mathrm{SLE} \mathrm{yr}^{-1} \mathrm{~K}^{-1}$ if glacier surface area weighted temperature anomaly is used, and on the order of $1.25 \mathrm{~mm} \mathrm{SLE} \mathrm{yr}^{-1} \mathrm{~K}^{-1}$ if global mean temperature anomaly is used. This contribution corresponds to the changes in solid precipitation and ablation. The decreased sensitivity of glacier surface area weighted temperature anomaly is consistent with the temperature amplification experienced by the glaciers (Fig. 5). Finally, a quadratic contribution of roughly $0.18 \mathrm{~mm} \mathrm{SLE} \mathrm{yr}^{-1} \mathrm{~K}^{-2}$ (glacier surface area weighted temperature) or $0.57 \mathrm{~mm} \mathrm{SLE} \mathrm{yr}^{-1} \mathrm{~K}^{-2}$ (global mean temperature) which - assuming that the length of the ablation season is linearly related to the annual mean temperature - is related to the interaction of changes in the length of ablation and accumulation seasons and changed temperature and solid precipitation.

Instead of applying the model specific parameters for the quadratic fit, it is also possible to apply the mean of the model specific parameters. The last column of Table 3 shows the RMSE of this model mean fitted curve. By this measure, the fit of the curve based on the glacier surface area weighted temperature anomaly is substantially better than the fit based on the global mean temperature anomaly (RMSE about half as big). This indicates that differences in the spatial patterns of the temperature anomaly are responsible for a considerable fraction of the different responses of global glacier mass to climate change. The remaining differences are due to the patterns in precipitation anomaly, history of the climate forcing, and different seasonalities of the temperature changes.

Based on a linear approximation, Gregory and Oerlemans (1998) estimate the linear sensitivity to $0.63 \mathrm{~mm} \mathrm{SLE} \mathrm{yr}^{-1} \mathrm{~K}^{-1}$, and Meehl et al. (2007) to $0.80 \pm 0.33 \mathrm{~mm} \mathrm{SLE} \mathrm{yr}^{-1} \mathrm{~K}^{-1}$ based on observations, and to $0.61 \pm 0.12$ or $0.49 \pm 0.13 \mathrm{~mm} \mathrm{SLE} \mathrm{yr}^{-1} \mathrm{~K}^{-1}$ based on different models (all using global mean temperature). To better understand our strongly enhanced sensitivity, we estimated a linear sensitivity for the case of fixed glacier hypsometry as before, but this time driving the glacier model with past, observed climate (Mitchell and Jones, 2005), essentially reproducing the method applied by Meehl et al. (2007) in our model. This experiment results in a linear sensitivity of $0.41 \pm 0.49 \mathrm{~mm} \mathrm{SLE} \mathrm{yr}^{-1} \mathrm{~K}^{-1}$, consistent with all the previous results (the error range given is the $95 \%$ confidence interval, and is large because of a relatively weak correlation of mass loss rates with global mean temperature anomalies). This indicates that the reason for the substantially different sensitivities when determined based on either future or past climate change is that the present glacier hypsometries have already responded to past climate change; that is, the actual sensitivity for a fixed reference hypsometry is high, but the sensitivity is strongly dampened by the glaciers' hypsometry response. This response has already had a considerable influence on past glacier mass change.

The temporally accumulated mass loss from the experiment with constant hypsometry and infinite volume is shown in Fig. 7. From this too it is apparent that changes in 
Table 3. Model mean parameters of a function of the form $a+b \cdot \Delta T+c \cdot \Delta T^{2} \cdot \frac{\Delta T}{\Delta T}$ fitted to the modeled global glacier mass balance when glacier hypsometry is held constant, and ice volume treated as infinite (Fig. 6). Standard deviation between CMIP5 models given as uncertainty. Last column: goodness-of-fit (RMSE) from applying the model mean parameters instead of the model-specific parameters.

\begin{tabular}{|c|c|c|c|c|c|}
\hline Scenario & & $\begin{array}{c}a \\
{\left[\frac{\mathrm{mm} \mathrm{SLE}}{\mathrm{yr}}\right]}\end{array}$ & $\begin{array}{c}b \\
{\left[\frac{\mathrm{mm} \mathrm{SLE}}{K \mathrm{yr}}\right]}\end{array}$ & $\begin{array}{c}c \\
{\left[\frac{\mathrm{mm} \mathrm{SLE}}{K^{2} \mathrm{yr}}\right]}\end{array}$ & $\begin{array}{c}\text { RMSE } \\
{\left[\frac{\mathrm{mm} \mathrm{SLE}}{\mathrm{yr}}\right]}\end{array}$ \\
\hline \multirow{2}{*}{$\mathrm{RCP} 2.6$} & global mean $\Delta T$ & $0.94 \pm 0.15$ & $1.19 \pm 0.36$ & $0.56 \pm 0.59$ & 1.19 \\
\hline & glacier surface area weighted $\Delta T$ & $0.92 \pm 0.14$ & $0.62 \pm 0.16$ & $0.16 \pm 0.09$ & 0.72 \\
\hline \multirow{2}{*}{$\mathrm{RCP} 4.5$} & global mean $\Delta T$ & $0.86 \pm 0.17$ & $1.24 \pm 0.45$ & $0.55 \pm 0.32$ & 2.96 \\
\hline & glacier surface area weighted $\Delta T$ & $0.91 \pm 0.16$ & $0.61 \pm 0.19$ & $0.17 \pm 0.07$ & 1.45 \\
\hline \multirow{2}{*}{ RCP6.0 } & global mean $\Delta T$ & $0.81 \pm 0.10$ & $0.97 \pm 0.44$ & $0.67 \pm 0.39$ & 1.22 \\
\hline & glacier surface area weighted $\Delta T$ & $0.86 \pm 0.08$ & $0.53 \pm 0.16$ & $0.20 \pm 0.06$ & 0.77 \\
\hline \multirow{2}{*}{ RCP8.5 } & global mean $\Delta T$ & $0.72 \pm 0.36$ & $1.65 \pm 1.23$ & $0.51 \pm 0.40$ & 9.74 \\
\hline & glacier surface area weighted $\Delta T$ & $0.74 \pm 0.47$ & $0.68 \pm 0.40$ & $0.19 \pm 0.06$ & 4.69 \\
\hline
\end{tabular}

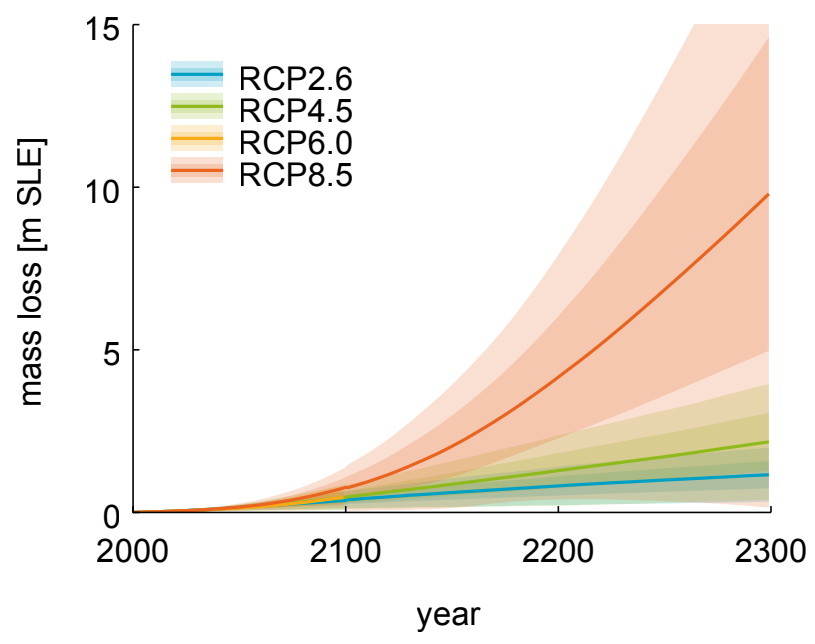

Fig. 7. Global glacier-mass loss when glacier hypsometry is held constant, and ice volume treated as infinite. Solid line is ensemble mean, dark/light shading indicates ensemble spread (one/two standard deviations).

glacier hypsometry and volume must impose strong limits on glacier-mass loss in reality, since the projected sea level rise far exceeds the (fixed) initial ice volume. Given the excessive projected mass loss of this experiment, it is clear that the ice mass must be the dominant limiting factor of future mass loss in all the scenarios, and for all climate models.

Plotting the temporally integrated glacier-mass loss of this experiment as a function of the temporally integrated mass loss of Marzeion et al. (2012, see Fig. 8) reveals that glacier hypsometry changes dampen the mass loss response of glaciers to climate change even for fairly small mass losses of less than $10 \mathrm{~mm}$ SLE, supporting the conclusion that the feedbacks considered here have already played a role in shaping the 20th century mass response of glaciers to climate change.

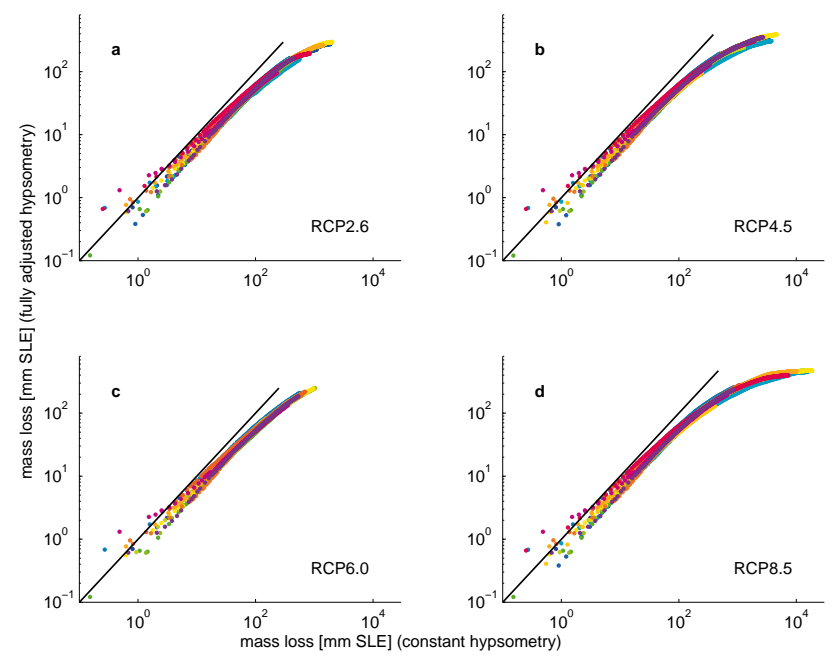

Fig. 8. Global glacier-mass loss of Marzeion et al. (2012) vs. global glacier-mass loss when glacier hypsometry is held constant, and ice volume treated as infinite. Black line is the bisector. Colors as in Fig. 2. Different panels refer to different RCPs.

\subsubsection{Constant terminus elevation}

Changes in glacier terminus elevation can be expected to provide a negative feedback to the glacier mass balance, since a glacier losing mass eventually retreats to higher elevation, where colder temperatures prevail. Without the possibility of a response of the glacier terminus to mass balance anomalies, glaciers cannot reach an equilibrium with a changed climate. Terminus elevation changes are neglected, for example, in the approach taken by van de Wal and Wild (2001) and Slangen and van de Wal (2011). Figure 9 shows that if this feedback is ignored, glaciers would lose substantially more mass under global warming. Figure 10 shows that the mass loss is not only greater under all scenarios, but also at almost all times the rates of mass loss are higher. The feedback is strongest in the RCP2.6 scenario, and weakest in the 

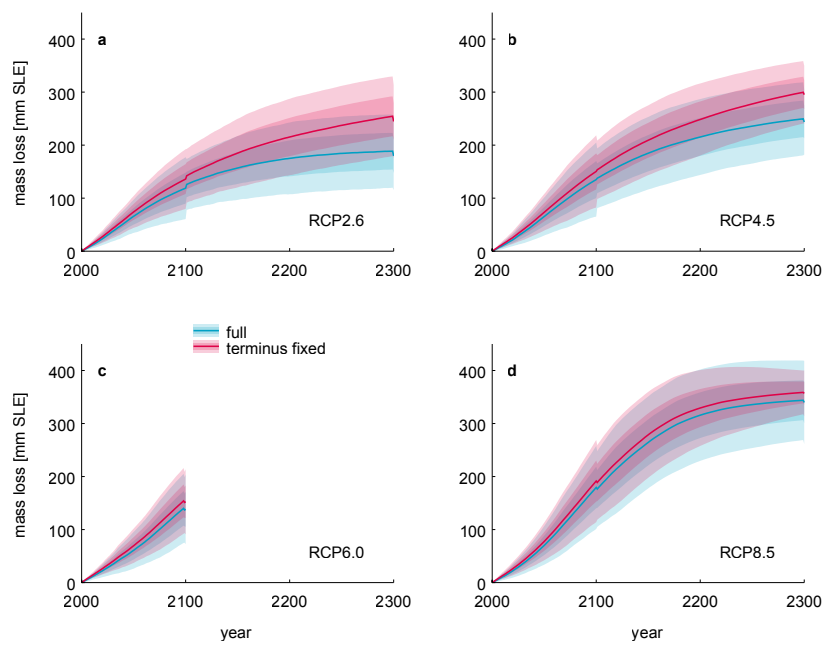

Fig. 9. Effect of fixed glacier terminus altitude on glacier mass change; "full" refers to the results of Marzeion et al. (2012) with fully responsive glacier hypsometry. Solid line is ensemble mean, dark/light shading indicates ensemble spread (one/two standard deviations). Different panels refer to different RCPs.

RCP8.5 scenario. The reason for this difference is the presence of glaciers that may be affected: in the RCP2.6 scenario, mass loss is relatively small and relatively few glaciers disappear completely, implying that many glaciers are affected by the feedback. But under a scenario of greater warming, many glaciers lose all their mass, implying that terminus elevation does not matter any longer for their mass balance. Figure 11, showing the difference in mass loss in 2300 (i.e., at a time when the fully responsive model is close to equilibrium) confirms that the effect of changing terminus elevations is largely a function of past mass loss, independent of climate model and RCP scenario. During the transient period, the relation between past mass loss and the terminus elevation feedback is more complex. The glacier terminus may be both higher or lower than its equilibrium value. Which is the case depends both on how strong climate variability is compared to climate change, and what the response time of the glacier is. Since the response times are different for each glacier, Fig. 11 becomes noisier at periods of strong mass loss rates.

\section{Discussion}

In the global view, glaciers are considerably out of balance with the climate of the recent past (Jacob et al., 2012; Gardner et al., 2013), and glacier-mass loss would continue even if climate changed no further. Using observed accumulation-area ratios, Mernild et al. (2013) come to the conclusion that glaciers are already committed to a mass loss of $16.3 \pm 7.3 \mathrm{~cm}$ SLE. While this estimate is higher than ours of $6.6 \pm 0.2 \mathrm{~cm} \mathrm{SLE}$, a direct comparison with our results is
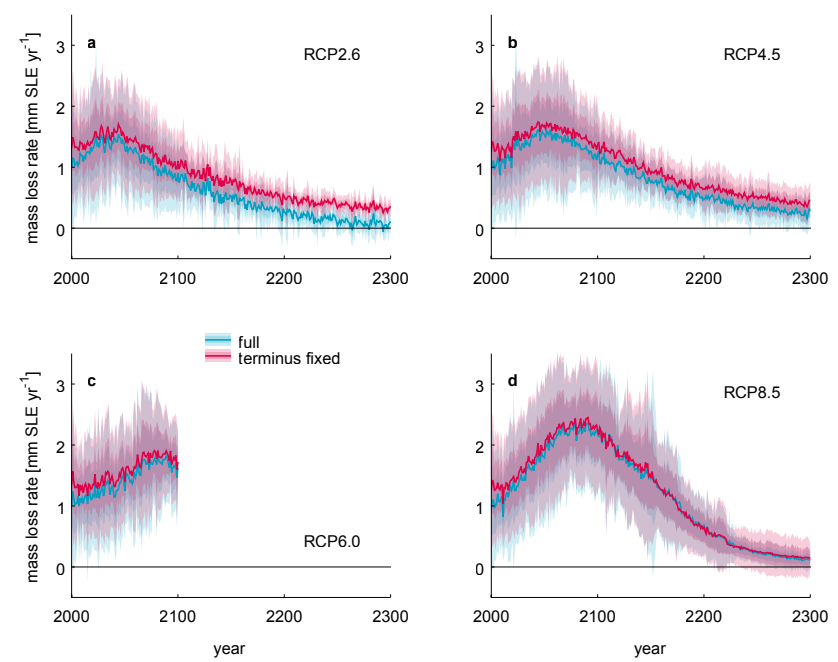

Fig. 10. Effect of fixed glacier terminus altitude on glacier mass change rates; "full" refers to the results of Marzeion et al. (2012) with fully responsive glacier hypsometry. Solid line is ensemble mean, dark/light shading indicates ensemble spread (one/two standard deviations). Different panels refer to different RCPs.

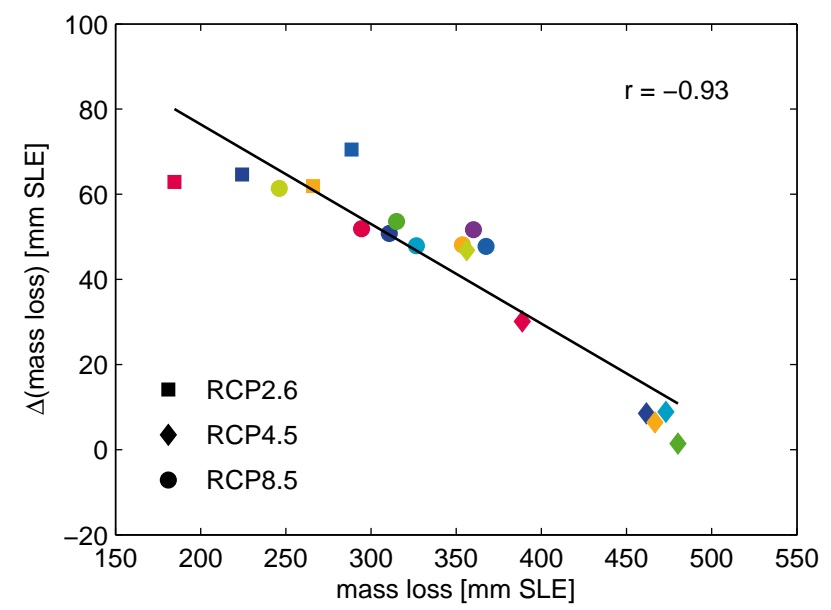

Fig. 11. Summary of the effect of glacier terminus retreat to higher altitude on glacier-mass loss. Plotted are the anomalies in the year 2300 as a function of respective mass loss projected in Marzeion et al. (2012) at the same time. Colors as in Fig. 2. Different markers refer to different RCPs.

not possible because of different reference times. But considering that they included observations up to 2010 which includes more negative mass balances than our reference period of 1961-1990, our estimate might be consistent with theirs. Glaciers' mass loss during the next decades is therefore to a large extent predetermined from the past. This helps explain why there is great similarity in glaciers response to widely differing climate scenarios (Marzeion et al., 2012; Radić et al., 2013). 
Our result that the wide ensemble spread within each RCP scenario to a large extent is attributable to differences in temperature anomaly patterns is in line with the results of Giesen and Oerlemans (2013), even though not directly comparable since their model involves - apart from precipitation atmospheric transmissivity as a forcing parameter. Giesen and Oerlemans (2013) also report that applying changes in temperature only increased the glaciers' response to future warming significantly, but the compensation by increasing precipitation in our case is not as strong as in theirs.

When comparing glacier surface area weighted to global mean temperature changes (Fig. 5), we neglected seasonality. This is problematic especially concerning the arctic amplification of global warming, which is stronger in winter than in summer, thereby having a lesser influence on glacier mass balance than a comparable temperature change of the annual mean (Gregory and Oerlemans, 1998). That said, Table 3 shows that the RMSE of fitting mass loss with area weighted temperature changes is about half as big as the RMSE when using global mean temperature change. This implies that differences in the temperature change patterns of the difference GCMs are responsible for about half of the differences in the mass losses - or in other words, area-weighted temperatures are a better predictor for glacier-mass loss than global mean temperatures, even if seasonality is neglected. The fit would probably improve further if seasonality was accounted for in the glacier surface area weighted temperature, but doing so is non-trivial, as the length of ablation and accumulation seasons is glacier specific, and variable in time.

Observed sea level rise during the 20th century can only be explained if the glaciers' contribution did not develop in parallel to global mean temperature, but was high already in the first half of the 20th century (Gregory et al., 2013). Our result that changes in glacier hypsometry play a significant role in shaping the glaciers' response to climate change, in particular that loss of low-lying surface area (i.e., terminus retreat to higher elevations) decreases the sensitivity is critical for explaining the strong glacier-mass losses during the first half of the 20th century. Being able to explain and account for this mechanism is also important for the ability of process-based projections of sea level rise (Church et al., 2013). Knowledge of the equilibrium response of glaciers to climate change is furthermore necessary in order to develop scenarios of longterm sea level rise (Levermann et al., 2013).

By providing a positive feedback on the mass balance, ice thickness changes may be more important than terminus retreat in determining the mass balance response to climate change for some glaciers (Raymond et al., 2005), particularly if the response of the glaciers is not dynamic (i.e., ice is melting over a large fraction or all of the surface), ice thickness change may become important (Paul and Haeberli, 2008). Similarly, for glaciers with long, flat tongues, even a dynamic response to volume change may not necessarily lead to strong changes in terminus elevation. The surface topography may change considerably nevertheless (Larsen et al., 2007; Bolch et al., 2008). Our glacier model does not explicitly account for ice thickness change and associated changes in the surface topography that are unrelated to surface area change and terminus elevation. It is therefore not possible to isolate this effect here. However, we argue that while ice thickness change is not considered explicitly, it is contained in the model implicitly - more specifically, in the glaciers' temperature sensitivity $\mu^{*}$ : the ice thickness-mass balance feedback increases a glacier's sensitivity to temperature change, by amplifying the temperature anomalies at the ice surface. Since $\mu^{*}$ is essentially calibrated by determining a value that results in the best fit to observations (which of course include the feedback), and since the cross validation of the model in Marzeion et al. (2012) does not indicate a significant bias of modeled mass balances, independent of the length of the observation time series, we can conclude that not explicitly including ice thickness changes in the model does not affect the reliability of the model's results. It would be feasible to explicitly include this mechanism, and it seems desirable to do so in order to be able to quantify it globally. We deliberately chose not to do this here, since it would require a complete recalibration of the model, which would inhibit the direct comparison with the results of (Marzeion et al., 2012). Moreover, the results of Paul (2010) and Huss et al. (2012) indicate that the combined effect of glacier surface topography changes is dampening the glaciers' response to climate forcing over long timescales, even though this may be arguably different for individual glaciers (Harrison et al., 2009). The increase of the sensitivity by a factor of two to three if glacier hypsometry is held constant reported by Paul (2010) for the European Alps is consistent with our results for the global scale.

Other potentially important feedbacks not included in the model but meriting thorough evaluation include, for example, changes of ice albedo due to accumulation of dust on melting glaciers (Oerlemans et al., 2009), and changes to the long-wave radiation energy budget from newly exposed rock faces surrounding the glacier.

\section{Conclusions}

We have used a model of glacier response to climate change to quantify the equilibrium sensitivity of glaciers, and to distinguish the respective contributions of temperature and precipitation anomalies. Because of the geographic distribution of glaciers, the temperature and precipitation change experienced by glaciers is far greater than the global mean. Precipitation anomalies projected for the future dampen the mass loss of glaciers, but their effect is strongly limited by the increasing temperatures, which increases the liquid fraction of precipitation on the glaciers.

We find that glacier-mass loss during the 21 st century is to a significant degree a response to 20th century climate change. This partly explains the relatively weak dependence 
of 21 st century mass loss on future greenhouse gas emissions. A second reason is that the complete loss of individual glaciers imposes a strong restriction to the rates of mass loss in a warming climate. Results from methods not accounting for finiteness of ice mass available for melting, for example, by extrapolating current rates of mass loss, or even increases of rates of mass loss (Meier et al., 2007), will therefore yield substantial overestimates.

Thirdly, changes of glacier hypsometry reduce the response of glaciers to warming, and need to be considered in explaining the observed rates of mass loss during the 20th century and the projected rates for the 21st century. Figure 9 summarizes our quantification of this effect. We find that the retreat of glacier termini to higher altitudes is a strong negative feedback, which is becoming weaker as more glaciers disappear completely.

Acknowledgements. This work was funded by the Austrian Science Fund (FWF): P22443-N21 and PP25362-N26, and supported by the Austrian Ministry of Science BMWF as part of the UniInfrastrukturprogramm of the Research Platform Scientific Computing at the University of Innsbruck. We would like to thank D. Farinotti, A. Gardner, and P. Leclercq for their constructive comments on an earlier version that helped us greatly to improve the manuscript.

Edited by: E. Larour

\section{References}

Andrews, T., Forster, P. M., Boucher, O., Bellouin, N., and Jones, A.: Precipitation, radiative forcing and global temperature change, Geophys. Res. Lett., 37, L14701, doi:10.1029/2010GL043991, 2010.

Arendt, A., Bolch, T., Cogley, G., Gardner, A., Hagen, J. O., Hock, R., Kaser, G., Paul, F., Radic, V., Bliss, A., Fountain, A., Mercer, A., Negrete, A., Giffen, B., Menounos, B., Kienholz, C., Mayer, C., Nuth, C., Burgess, D., Hall, D., Kriegel, D., Berthier, E., Burgess, E., Cawkwell, F., Wyatt, F., Hartmann, G., Wolken, G., Frey, H., Brown, I., Howat, I., Lund, J., Rich, J., Filbert, K., Andreassen, L., Copland, L., Beedle, M., Koenig, M., Sharp, M., Moelg, N., Sigurdsson, O., Rastner, P., Forester, R., LeBris, R., Pettersson, R., Wheate, R., Herreid, S., Vorogushin, S., Winsvold, S., Chinn, T., Hagg, W., and Manley, W.: Randolph Glacier Inventory 1.0: A Dataset of Global Glacier Outlines, global Land Ice Measurements from Space, Boulder Colorado, USA, Digital Media, 2012.

Bahr, D.: Global distributions of glacier properties: a stochastic scaling paradigm, Water Resour. Res., 33, 1669-1679, 1997.

Bahr, D., Meier, M., and Peckham, S.: The physical basis of glacier volume-area scaling, J. Geophys. Res., 102, 355-362, 1997.

Barrand, N., Hindmarsh, R., Arthern, R., Williams, C. R., Mouginot, J., Scheuchl, B., Rignot, E., Ligtenberg, S., van den Broeke, M., Edwards, T., Cook, A. J., and Simonsen, S. B.: Computing the volume response of the Antarctic Peninsula ice sheet to warming scenarios to 2200, J. Glaciol., 59, 397-409, 2013.

Bolch, T., Buchroithner, M., Pieczonka, T., and Kunert, A.: Planimetric and volumetric glacier changes in the Khumbu Himal,
Nepal, since 1962 using Corona, Landsat TM and ASTER data, J. Glaciol., 54, 592-600, 2008.

Church, J. A., Monselesan, D., Gregory, J. M., and Marzeion, B.: Evaluating the ability of process based models to project sealevel change, Environ. Res. Lett., 8, 014051, doi:10.1088/17489326/8/1/014051, 2013.

Cogley, J. G.: Geodetic and direct mass-balance measurements: comparison and joint analysis, Ann. Glaciol., 50, 96-100, doi:10.3189/172756409787769744, 2009.

Ehlschlaeger, C.: Using the $\mathrm{A}^{T}$ search algorithm to develop hydrologic models from digital elevation data, in: International Geographic Information Systems (IGIS) Symposium, Vol. 89, 275281, 1989.

Gardner, A. S., Moholdt, G., Cogley, J. G., Wouters, B., Arendt, A. A., Wahr, J., Berthier, E., Hock, R., Pfeffer, W. T., Kaser, G., Ligtenberg, S. R. M., Bolch, T., Sharp, M. J., Hagen, J. O., van den Broeke, M. R., and Paul, F.: A reconciled estimate of glacier contributions to sea level rise: 2003 to 2009, Science, 340 , 852-857, 2013.

Giesen, R. H. and Oerlemans, J.: Climate-model induced differences in the 21 st century global and regional glacier contributions to sea-level rise, Clim. Dynam., 41, 3283-3300, doi:10.1007/s00382-013-1743-7 2013.

Gregory, J. M. and Oerlemans, J.: Simulated future sea-level rise due to glacier melt based on regionally and seasonally resolved temperature changes, Nature, 391, 474-476, 1998.

Gregory, J. M., Church, J. A., White, N. J., Bierkens, M. F. P., Box, J. E., van den Broeke, M., G., C. J., Fettweis, X., Hanna, E., Leclercq, P. W., Marzeion, B., Oerlemans, J., Wada, Y., Wake, L. M., and van de Wal, R. S. W.: Twentieth-century global-mean sea-level rise: is the whole greater than the sum of the parts?, J. Climate, 26, 4476-4499, doi:10.1175/JCLI-D-12-00319.1, 2013.

Grinsted, A.: An estimate of global glacier volume, The Cryosphere, 7, 141-151, doi:10.5194/tc-7-141-2013, 2013.

Harrison, W. D., Cox, L. H., Hock, R., March, R. S., and Pettit, E. C.: Implications for the dynamic health of a glacier from comparison of conventional and reference-surface balances, Ann Glaciol., 50, 25-30, 2009.

Hock, R.: Temperature index melt modelling in mountain areas, J. Hydrol., 282, 104-115, doi:10.1016/S0022-1694(03)00257-9, 2003.

Huss, M.: Extrapolating glacier mass balance to the mountain-range scale: the European Alps 1900-2100, The Cryosphere, 6, 713727, doi:10.5194/tc-6-713-2012, 2012.

Huss, M. and Farinotti, D.: Distributed ice thickness and volume of all glaciers around the globe, J. Geophys. Res., 117, F04010, doi:10.1029/2012JF002523, 2012.

Huss, M., Hock, R., Bauder, A., and Funk, M.: Reply to the Comment of Leclercq et al. on "100-year mass changes in the Swiss Alps linked to the Atlantic Multidecadal Oscillation", The Cryosphere Discuss., 4, 2587-2592, doi:10.5194/tcd-4-25872010, 2010.

Huss, M., Hock, R., Bauder, A., and Funk, M.: Conventional versus reference-surface mass balance, J. Glaciol., 58, 278-286, 2012.

Jacob, T., Wahr, J., Pfeffer, W. T., and Swenson, S.: Recent contributions of glaciers and ice caps to sea level rise, Nature, 482, 514-518, 2012. 
Jóhannesson, T., Raymond, C., and Waddington, E.: Time-scale for adjustment of glaciers to changes in mass balance, J. Glaciol., 35, 355-369, 1989.

Larsen, C. F., Motyka, R. J., Arendt, A. A., Echelmeyer, K. A., and Geissler, P. E.: Glacier changes in southeast Alaska and northwest British Columbia and contribution to sea level rise, J. Geophys. Res., 112, F01007, doi:10.1029/2006JF000586, 2007.

Leclercq, P. W., van de Wal, R. S. W., and Oerlemans, J.: Comment on "100-year mass changes in the Swiss Alps linked to the Atlantic Multidecadal Oscillation" by Matthias Huss et al. (2010), The Cryosphere Discuss., 4, 2475-2481, doi:10.5194/tcd-42475-2010, 2010.

Leclercq, P. W., Oerlemans, J., and Cogley, J. G.: Estimating the Glacier Contribution to Sea-Level Rise for the Period 1800 2005, Surv. Geophys., 32, 519-535, doi:10.1007/s10712-0119121-7, 2011.

Levermann, A., Clark, P. U., Marzeion, B., Milne, G. A., Pollard, D., Radić, V., and Robinson, A.: The multi-millennial sealevel commitment of global warming, P. Natl. A. Sci. USA, 110, 13745-13750, doi:10.1073/pnas.1219414110, 2013.

Manabe, S., Stouffer, R., Spelman, M., and Bryan, K.: Transient responses of a coupled ocean-atmosphere model to gradual changes of atmospheric $\mathrm{CO}_{2}$. Part I: Annual mean response, J. Climate, 4, 785-818, 1991.

Marzeion, B., Jarosch, A. H., and Hofer, M.: Past and future sealevel change from the surface mass balance of glaciers, The Cryosphere, 6, 1295-1322, doi:10.5194/tc-6-1295-2012, 2012.

Meehl, G. A., Stocker, T. F., Collins, W. D., Friedlingstein, P., Gaye, A. T., Gregory, J. M., Kitoh, A., Knutti, R., Murphy, J. M., Noda, A., Raper, S. C. B., Watterson, I. G., Weaver, A. J., Zhao, Z.C., et al.: Global Climate Projections, in: Climate Change 2007: The Physical Science Basis. Contribution of Working Group I to the Fourth Assessment Report of the Intergovernmental Panel on Climate Change, edited by: Solomon, S., Qin, D., Manning, M., Chen, Z., Marquis, M., Averyt, K. B., M., T., and Miller, H. L., Cambridge University Press, Cambridge, UK and New York, NY, USA, 2007.

Meier, M. F., Dyurgerov, M. B., Rick, U. K., O’Neel, S., Pfeffer, W. T., Anderson, R. S., Anderson, S. P., and Glazovsky, A. F.: Glaciers dominate eustatic sea-level rise in the 21 st century, Science, 317, 1064-1067, doi:10.1126/science, 2007.

Mernild, S. H., Lipscomb, W. H., Bahr, D. B., Radić, V., and Zemp, M.: Global glacier retreat: a revised assessment of committed mass losses and sampling uncertainties, The Cryosphere Discuss., 7, 1987-2005, doi:10.5194/tcd-7-1987-2013, 2013.

Mitchell, T. D. and Jones, P. D.: An improved method of constructing a database of monthly climate observations and associated high-resolution grids, Int. J. Climatol., 25, 693-712, doi:10.1002/joc.1181, 2005.

New, M., Lister, D., Hulme, M., and Makin, I.: A high-resolution data set of surface climate over global land areas, Clim. Res., 21, $1-25,2002$.

Oerlemans, J.: Glaciers and Climate Change, A. A. Balkema Publishers, Lisse, Abingdon, Exton, Tokyo, 2001.
Oerlemans, J., Anderson, B., Hubbard, A., Huybrechts, P., Johannesson, T., Knap, W. H., Schmeits, M., Stroeven, A. P., van de Wal, R. S. W., Wallinga, J., and Zuo, Z.: Modelling the response of glaciers to climate warming, Clim. Dynam., 14, 267274, 1998.

Oerlemans, J., Giesen, R., and Van Den Broeke, M.: Retreating alpine glaciers: increased melt rates due to accumulation of dust (Vadret da Morteratsch, Switzerland), J. Glaciol., 55, 729-736, 2009.

Ohmura, A.: Physical Basis for the Temperature-Based Melt-Index Method, J. Appl. Meteorol., 40, 753-761, 2001.

Paul, F.: The influence of changes in glacier extent and surface elevation on modeled mass balance, The Cryosphere, 4, 569-581, doi:10.5194/tc-4-569-2010, 2010.

Paul, F. and Haeberli, W.: Spatial variability of glacier elevation changes in the Swiss Alps obtained from two digital elevation models, Geophys. Res. Lett., 35, L21502, doi:10.1029/2008GL034718, 2008.

Radić, V., Bliss, A., Beedlow, A. C., Hock, R., Miles, E., and Cogley, J. G.: Regional and global projections of 21 st century glacier mass changes in response to climate scenarios from global climate models, Clim. Dynam., 42, 37-58, 2013.

Raymond, C., Neumann, T. A., Rignot, E., Echelmeyer, K., Rivera, A., and Casassa, G.: Retreat of Glaciar Tyndall, Patagonia, over the last half-century, J. Glaciol., 51, 239-247, 2005.

Screen, J. A. and Simmonds, I.: The central role of diminishing sea ice in recent Arctic temperature amplification, Nature, 464, 1334-1337, 2010.

Sicart, J., Hock, R., and Six, D.: Glacier melt, air temperature, and energy balance in different climates: The Bolivian Tropics, the French Alps, and northern Sweden, J. Geophys. Res., 113, D24113, doi:10.1029/2008JD010406, 2008.

Slangen, A. B. A. and van de Wal, R. S. W.: An assessment of uncertainties in using volume-area modelling for computing the twenty-first century glacier contribution to sea-level change, The Cryosphere, 5, 673-686, doi:10.5194/tc-5-673-2011, 2011.

Sutton, R. T., Dong, B., and Gregory, J. M.: Land/sea warming ratio in response to climate change: IPCC AR4 model results and comparison with observations, Geophys. Res. Lett., 34, L02701, doi:10.1029/2006GL028164, 2007.

van de Wal, R. and Wild, M.: Modelling the response of glaciers to climate change by applying volume-area scaling in combination with a high resolution GCM, Clim. Dynam., 18, 359-366, doi:10.1007/s003820100184, 2001.

van Vuuren, D. P., Edmonds, J., Kainuma, M., Riahi, K., Thomson, A., Hibbard, K., Hurtt, G. C., Kram, T., Krey, V., Lamarque, J.-F., Masui, T., Meinhausen, M., Nakicenovic, N., Smith. S. J., and Rose, S. K.: The representative concentration pathways: an overview, Clim. Change, 109, 5-31, 2011.

Zuo, Z. and Oerlemans, J.: Contribution of glacier melt to sea-level rise since $\mathrm{AD}$ 1865: a regionally differentiated calculation, Clim. Dynam., 13, 835-845, 1997. 